\title{
Hypercapnic Respiratory Failure in Case of Chiari 1.5 Malformation: Case Report and Review of the Literature
}

\author{
Viralkumar M. Vasani, Subhas Kanti Konar', S. Satish \\ Department of Neurosurgery, Fortis Hospitals, 'Department of Neurosurgery, NIMHANS, Bengaluru, Karnataka, India
}

\section{Abstract}

Type 2 respiratory failure is defined as hypercapnia associated with hypoxia. Chiari 1.5 is known as herniation of the cerebellar tonsils along with brain stem and fourth ventricle. We report a 35-year-old male who presented with acute hypercapnic respiratory failure (Type 2), without any preexisting neurological or respiratory abnormality. Analysis of blood gases in emergency revealed a $\mathrm{pH}^{\circ} \mathrm{of} .12, \mathrm{pCO}_{2}$ of $132 \mathrm{mmHg}$, and arterial oxygen tension of $118 \mathrm{~mm} \mathrm{Hg}$. He was intubated and ventilated. Magnetic resonance imaging brain revealed herniation of the cerebellar tonsils along with brain stem and fourth ventricle. The patient underwent surgery and gradually weaned off. He was mobilized and discharged on day 6. Acute respiratory failure has not been reported with Chiari 1.5 malformation. The lesson to be learned from this case is that craniospinal pathology must be looked for in a patient with hypercapnic respiratory failure.

Keywords: Chiari 1.5 malformation, hypercapnic respiratory failure, outcome, radiology, syringomyelia

\section{INTRODUCTION}

Chiari 1.5 malformation is an evolving new terminology in relation to craniospinal dysraphic conditions. Characteristics of Chiari 1.5 include caudal migration of cerebellar tonsils as well as brainstem and fourth ventricle ${ }^{[1]}$ Chiari Type 1 malformation has a variety of clinical presentations in relation to the respiratory system as a result of brain stem respiratory center involvement such as central alveolar hypoventilation, sleep apnea, and acute respiratory failure. ${ }^{[2]}$ Further, the association with cervical syrinx may cause intercostal weakness or diaphragmatic palsy resulting in respiratory failure. ${ }^{[3]}$ Only few case reports are available of Chiari 1 malformation presenting solely with respiratory failure without any prior neurological symptoms. ${ }^{[3,4]}$

We are reporting the first case of a 35-year-old man who presented with hypercapnic acute respiratory failure without any prior neurological manifestations and later was diagnosed to have Chiari 1.5 malformation.

\section{Case Report}

A 35-year-old male presented with a 10-day history of breathlessness, which gradually progressed from Modified Medical Research Council (MMRC) dyspnea scale of

\begin{tabular}{|l|l|}
\hline \multicolumn{3}{|c|}{ Access this article online } \\
\hline Quick Response Code: & Website: \\
\hline
\end{tabular}

1 to MMRC 3. This was not associated with chest pain or fever. The patient was admitted in casualty and peripheral capillary oxygen saturation showed $72 \%$. Arterial blood gas analysis showed $\mathrm{pCO}_{2}-132 \mathrm{~mm} \mathrm{Hg}, \mathrm{pO}_{2}-118 \mathrm{mmHg}$, and $\mathrm{pH}$ of 7.21 . He was unresponsive, intubated, and started on mechanical ventilation. Gradually, he improved in the sensorium. He did not have any history of neck pain, weakness of limbs, or sensory symptoms. He was investigated with computer tomography (CT) chest to rule out pulmonary embolism or pneumonia. Cardiac evaluation was done to rule out any local cause of respiratory failure. CT of head showed no intracranial lesion [Figure 1a]. However, CT head [reconstruction image, Figure 1b] showed crowding at the foramen magnum and descent of tonsils. Magnetic resonance imaging (MRI) craniovertebral junction revealed descent of the cerebellar tonsils up to $\mathrm{C} 2$, along with the caudal descent of brain stem and fourth ventricle. The angulation of odontoid was $58.8^{\circ}$ and syringomyelia was extending from $\mathrm{C} 1-\mathrm{C} 5$ level [Figure 1c-e]. He underwent foramen magnum decompression, $\mathrm{C} 1$ arch Address for correspondence: Dr. Subhas Kanti Konar,
Department of Neurosurgery, NIMHANS, Hosur Road,
Bengaluru - 560 029, Karnataka, India.
E-mail: drsubhaskonar@gmail.com

This is an open access article distributed under the terms of the Creative Commons Attribution-NonCommercial-ShareAlike 3.0 License, which allows others to remix, tweak, and build upon the work non-commercially, as long as the author is credited and the new creations are licensed under the identical terms.

For reprints contact: reprints@medknow.com

How to cite this article: Vasani VM, Konar SK, Satish S. Hypercapnic respiratory failure in case of chiari 1.5 malformation: Case Report and review of the literature. Indian J Crit Care Med 2017;21:707-9. 


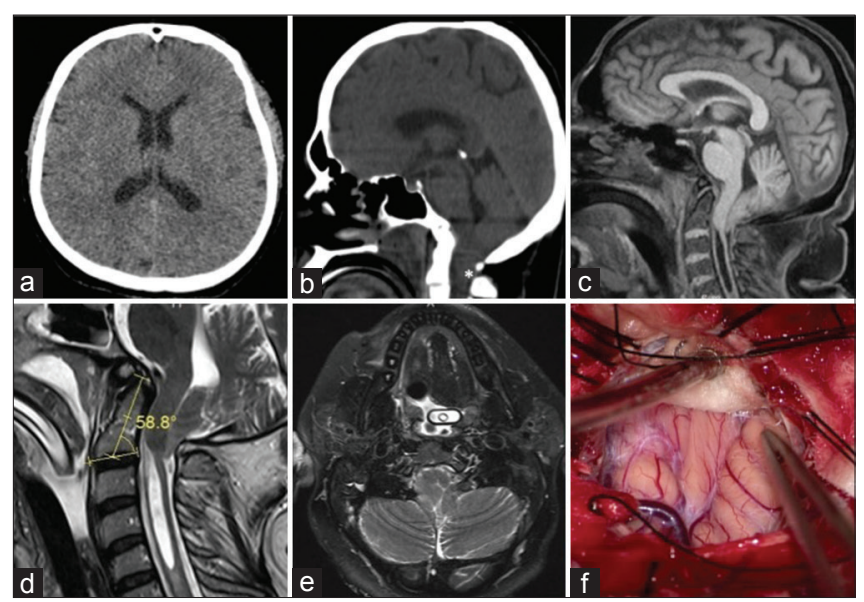

Figure: 1: (a) Computed tomography head showed no parenchymal lesion and no hydrocephalus. (b) Computed tomography craniocervical junction (Sagittal) showed crowding at foramen magnum and descent of tonsils $\left(^{*}\right)$. (c) Magnetic resonance imaging craniocervical junction (T1 weighted, Sag) showed herniation of brainstem and fourth ventricle and cervical syrinx. (d) Magnetic resonance imaging craniocervical junction (T2 weighted, Sag) showed the descent of tonsils and angulation of odontoid $\left(58.8^{\circ}\right)$ suggestive of Chiari 1.5 malformation. (e) Magnetic resonance imaging craniocervical junction (T2 weighted, axial) showed crowding at the foramen magnum. (f) Intraoperative image showed the asymmetrical descent of tonsils (left $>$ right) suggestive of Chiari 1.5 malformation

excision with partial removal of upper part of $\mathrm{C} 2$. There was an asymmetrical descent of tonsils (left $>$ right) [Figure 1f] and extensive arachnoid adhesions. The lower poles of both tonsils were coagulated with bipolar diathermy. Adequate decompression was achieved, arachnoid released, and cerebrospinal fluid pathway was reestablished. Lax duraplasty was done with pericranial graft. Elective ventilation was continued for 1 day and then weaned off to noninvasive ventilator support (2:2). Gradually, this was reduced to $1 \mathrm{~h}$ three times in a day. Night $\mathrm{pCO}_{2}$ levels improved to $40 \mathrm{mmHg}$. He was then started on physical therapy, and he showed significant improvement both functionally and neurologically. He was discharged on postoperative day 6. At 1-month follow-up, he was ambulant and taking feeds orally without any difficulty.

\section{Discussion}

The clinical manifestations and radiological features of Chiari 1.5 malformation are nearly identical with that of Chiari 1 malformation except herniation of obex, angulation of the odontoid process $\left(84.4^{\circ}\right.$ vs. $\left.98.0^{\circ}\right)$, incidence of scoliosis $(27 \%$ vs. $17 \%)$, hydrocephalus $(9.1 \%$ vs. $11 \%$ ), and syringomyelia (50\% vs. $58 \%$ ). ${ }^{[5]}$ The abnormal clivus-canal angle and retroflexion of the odontoid are diagnostic characteristics of Chiari 1.5 malformation. In our case, the tonsillar herniation was $18.17 \mathrm{~mm}$, angulation of odontoid $-58.8^{\circ}$, and clivus-canal angle was $133.1^{\circ}$.

Chiari malformation Type 1 may be associated with various acute or chronic respiratory disorders. Acute respiratory conditions including Type 2 respiratory failure due to central alveolar hypoventilation and acute respiratory insufficiency due to diaphragmatic palsy are known to be associated with Chiari 1 malformation. ${ }^{[2]} \mathrm{A}$ chronic condition such as sleep-disordered breathing or sleep apnea syndrome has also been described in Chiari 1 malformation (70\%) as well as Chiari 2 malformation (30\%). ${ }^{[2]}$ Breathing cycle is a sophisticated automatic pathway controlled by respiratory centers in the brainstem. ${ }^{[3]}$ Information is received through peripheral chemoreceptors depending on diverse metabolic conditions. However, the above-mentioned respiratory conditions are not reported in association with Chiari 1.5 malformation. In our case, the patient had only Type 2 respiratory failure as the predominant presentation without any neurological symptoms. The respiratory failure was probably due to herniation of brain stem affecting the respiratory center causing central alveolar hypoventilation reflecting in the form of elevated $\mathrm{pCO}_{2}(132)$. The patient showed an excellent recovery after foramen magnum decompression $\left(\mathrm{pCO}_{2}-41\right)$.

In Chiari 1 malformation with respiratory failure, foramen magnum decompression has been shown to be adequate to bring about a recovery from respiratory failure. ${ }^{[4]}$ In the case of Chiari malformation 1.5, the surgical aim should be adequate foramen magnum decompression with or without tonsillectomy or tonsillar tip coagulation. Fenestration of arachnoid band or veil is needed for the better surgical outcome. ${ }^{[2]}$ In one report, the occurrence of persistent syringomyelia following posterior fossa decompressive surgery was higher in Chiari 1.5 malformation (13.6\%) than in Chiari I malformation (6.9\%). ${ }^{[5]}$ The alternative treatment option for persistent syrinx was syringe-subarachnoid shunt or redoes posterior fossa decompression. ${ }^{[2]}$ In our case of Chiari 1.5 malformation with Type 2 respiratory failure, the patient had a significant improvement in his respiratory status after posterior fossa decompression and tonsillar tip coagulation.

\section{Conclusion}

We report the first case of Chiari 1.5 malformation presenting with hypercapnic respiratory failure. Prompt neuroimaging and adequate posterior fossa decompression with tonsillar tip coagulation have a superior surgical outcome in such a condition.

\section{Declaration of patient consent}

The authors certify that they have obtained all appropriate patient consent forms. In the form, the patient has given his consent for his images and other clinical information to be reported in the journal. The patient understands that name and initial will not be published and due efforts will be made to conceal his identity, but anonymity cannot be guaranteed.

\section{Financial support and sponsorship}

Nil.

\section{Conflicts of interest}

There are no conflicts of interest. 


\section{References}

1. Tubbs RS, Iskandar BJ, Bartolucci AA, Oakes WJ. A critical analysis of the Chiari 1.5 malformation. J Neurosurg 2004;101 2 Suppl:179-83.

2. Dauvilliers Y, Stal V, Abril B, Coubes P, Bobin S, Touchon J, et al. Chiari malformation and sleep related breathing disorders. J Neurol Neurosurg Psychiatry 2007;78:1344-8.
3. Al Bashapshe A, Bhatia $\mathrm{H}$, Aziz S. Acute respiratory failure as a first manifestation of syringomyelia. Lung India 2010;27:93-5.

4. Alvarez D, Requena I, Arias M, Valdés L, Pereiro I, De la Torre R. Acute respiratory failure as the first sign of Arnold-Chiari malformation associated with syringomyelia. Eur Respir J 1995;8:661-3.

5. Kim IK, Wang KC, Kim IO, Cho BK. Chiari 1.5 malformation: An advanced form of Chiari I malformation. J Korean Neurosurg Soc 2010;48:375-9. 